\title{
Clinical outcome of endoscopic hemostasis with heater probe coagulation for bleeding gastric ulcer
}

Yoshihiro Inoue*, Yasuhisa Fujino, Makoto Onodera, Satoshi Kikuchi, Masayuki Sato, Hisaho Sato, Hironobu Noda, Masahiro Kojika, Yasushi Suzuki and Shigeatsu Endo

*Correspondence: yinoue@iwate-med.ac.jp

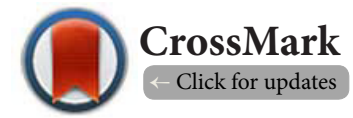

Department of Critical Care Medicine, School of Medicine, Iwate Medical University, Japan.

\begin{abstract}
We reviewed 1,152 patients with bleeding gastric ulcer treated at our institution between 1987 and 2011. Of these, 1,026 patients (89.1\%) underwent endoscopic hemostasis. Forrest classification for bleeding ulcers in these cases was as follows: Ia, 188 patients (18.3\%); Ib, 114 patients (11.1\%); and IIa, 665 patients (64.8\%). Endoscopic treatment proved successful in 1,023 patients (99.7\%), including 70 patients $(6.8 \%)$ who experienced re-bleeding. There were 19 deaths (1.9\%), and 3 patients (0.3\%) underwent surgical procedures. No surgical procedures were performed after 1994.
\end{abstract}

Keywords: Hemorrhagic gastric ulcer, endoscopic hemostasis, upper gastrointestinal hemorrhage, heater probe coagulation

\section{Introduction}

Bleeding gastric ulcer is the most common form of upper gastrointestinal hemorrhage. Up until the 1970s, surgical intervention represented the main treatment option for bleeding ulcers, including those in the duodenum. Endoscopic treatment was developed in the 1980s and subsequently became the firstline treatment, and most patients can now be successfully treated endoscopically. However, endoscopic treatment is not successful in all patients, and surgical intervention or interventional radiology (IVR) remain as secondary options. This study reports on our analysis of the efficacy of endoscopic treatment for bleeding gastric ulcers at our medical institution.

\section{Case presentation}

Subjects

This study included 1,152 patients (855 men, 297 women) treated at our institution for bleeding gastric ulcer between 1987 and 2011. Mean age at the time of medical examination was 55.1 years (men, 53.3 years; women, 60.4 years). The method of endoscopic hemostasis used for bleeding ulcers at our institution is thermal coagulation with a heater probe. Two representative cases are described below.

\section{Case 1}

The patient was a 57-year-old man who vomited blood and was brought to the hospital by ambulance. Blood pressure on arrival was $86 / 50 \mathrm{mmHg}$, heart rate was 112 beats/min, and he was in a state of shock. Blood tests revealed: red blood cell count (RBC), $264 \times 10^{4} / \mu \mathrm{L}$; hemoglobin $(\mathrm{Hb}), 8.4 \mathrm{~g} / \mathrm{dL}$; blood urea nitrogen (BUN), $38.6 \mathrm{mg} / \mathrm{dL}$; and creatinine (CRNN), $0.8 \mathrm{mg} / \mathrm{dL}$. Emergency endoscopy (Figure 2) revealed an ulcer in the lesser curvature of the angle of the stomach with arterial bleeding. A hemostatic procedure was performed using heater probe coagulation, and the patient was hospitalized. He recovered well and did not experience re-bleeding, and was discharged from hospital 7 days later.

\section{Case 2}

The patient was a 45-year-old man with a chief complaint of syncope. He had previously been diagnosed with hypertension, but this condition had been left untreated. He was brought to the emergency room after losing consciousness for approximately 3 min while attempting to stand up to use the washroom. He was conscious and lucid on initial examination, but blood pressure was $75 / 52 \mathrm{mmHg}$ and heart rate was 107 beats/ min, and he was in a state of shock. Blood tests revealed: RBC count, 427×10 $/ \mu \mathrm{L} ; \mathrm{Hb}, 13.3 \mathrm{~g} / \mathrm{dL}$; BUN, $22.9 \mathrm{mg} / \mathrm{dL}$; and CRNN, $0.9 \mathrm{mg} / \mathrm{dL}$. Transfusion raised his blood pressure, but he was admitted for observation, particularly because of untreated diabetes. Two days later, he vomited blood and went into shock a second time. Blood testing revealed profound anemia, with: $\mathrm{RBC}, 147 \times 10^{4} / \mu \mathrm{L} ; \mathrm{Hb}, 4.8 \mathrm{~g} / \mathrm{dL} ; \mathrm{BUN}, 42.0 \mathrm{mg} / \mathrm{dL}$; and CRNN, 
Inoue et al. Gastroenterological and Intestinal Systems 2014,

http://www.hoajonline.com/journals/pdf/2054-4154-2-1.pdf

$0.7 \mathrm{mg} / \mathrm{dL}$. Emergency endoscopic examination revealed a Dieulafoy ulcer with Forrest la bleeding in the lesser curvature of the stomach (Figure 3). Hemostasis was attempted and successfully established using a heater probe. Blood transfusion resulted in improvement of anemia, and no re-bleeding was encountered. Diabetes was brought under control, and he was discharged from the hospital 27 days later.

\section{Results}

When a patient with gastrointestinal bleeding is brought to our hospital after office hours, an outpatient physician provides initial treatment, and calls a full-time gastroenterological endoscopist, who takes over patient care on arrival. After preparation for endoscopy, the full-time physician undertakes endoscopic examination and treatment, and intravenously administers a proton pump inhibitor (PPI) if an ulcer is detected. In cases of upper gastrointestinal bleeding, endoscopy is performed on Day 2 of admission, and additional treatment is provided as necessary. If serious underlying disease or complications are absent, oral feeding will be started following completion of the endoscopy. For patients with ulcer bleeding, a PPI will be administered orally. If no re-bleeding is observed, even patients with ulcer bleeding will be discharged within approximately 1 week.

Table 1 shows the number of patients with upper gastrointestinal bleeding treated at our institution. Of the 3,466 patients, 1,152 patients (approximately one-third) were diagnosed with gastric ulcer. If the 483 patients with duodenal ulcer were included, the number of patients with bleeding ulcer increased to nearly half of the total number of patients. Figure 1 shows annual changes in numbers of patients with a bleeding ulcer. Since the peak in 2000, this number has shown a decreasing trend, although at least 30 patients have been treated every year. Of the 1,152 patients with bleeding gastric ulcer, those treated with endoscopic hemostasis using a heater probe totaled 1,026 (89.1\%). Forrest classification of bleeding [1] for these 1,026 patients was as follows: la,

Table 1. The cases of upper gastrointestinal bleeding from 1987 to 2011.

\begin{tabular}{lll}
\hline & No. of cases & \% \\
\hline Gastric ulcer & 1152 & $33.2 \%$ \\
Varix & 798 & 23.0 \\
Duodenal ulcer & 483 & 13.9 \\
Mallory-Weiss syndrome & 285 & 8.2 \\
Esophageal bleeding & 274 & 7.9 \\
AGML & 214 & 6.2 \\
Malignant disease & 93 & 2.7 \\
Stomal ulcer & 69 & 2.1 \\
Iatrogenic bleeding & 55 & 1.6 \\
Others & 43 & 1.2 \\
Total & 3466 & 100 \\
\hline
\end{tabular}

AGML: Acute gastric mucosal legion

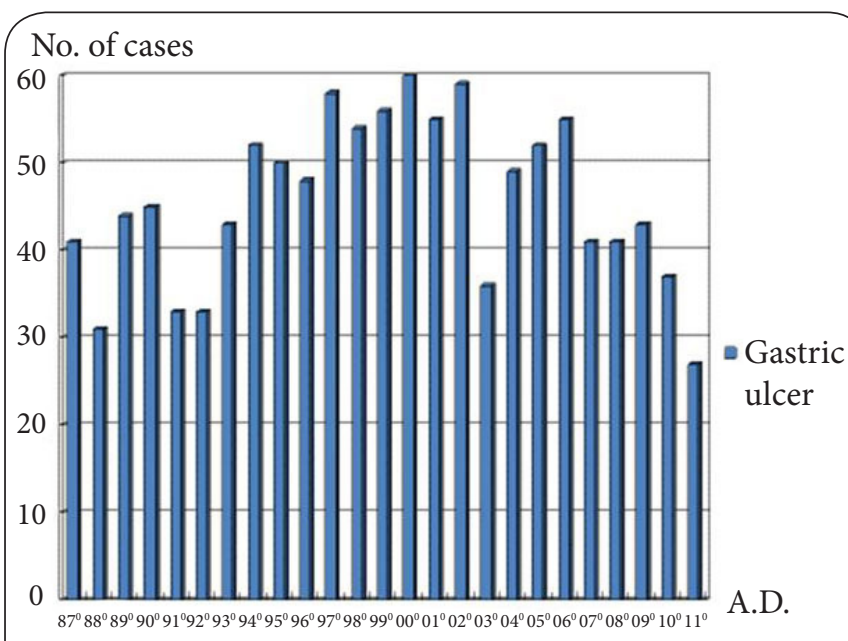

Figure 1. The number of gastric ulcer cases from 1987 to 2011.

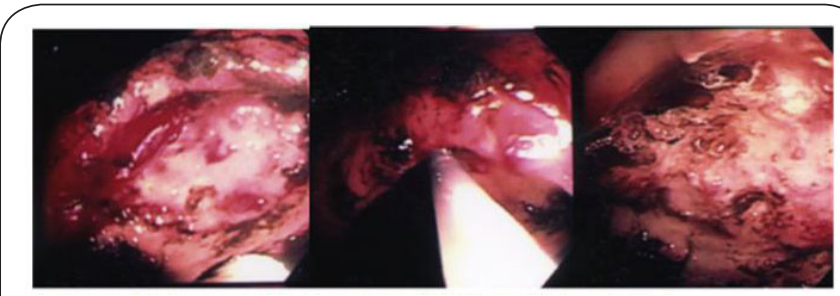

Figure 2. Endoscopic hemostasis with heater probe of case 1. Left: Arterial bleeding of gastric ulcer.

Middle: Endoscopic treatment with the heater probe.

Right: Successful endoscopic hemostasis.

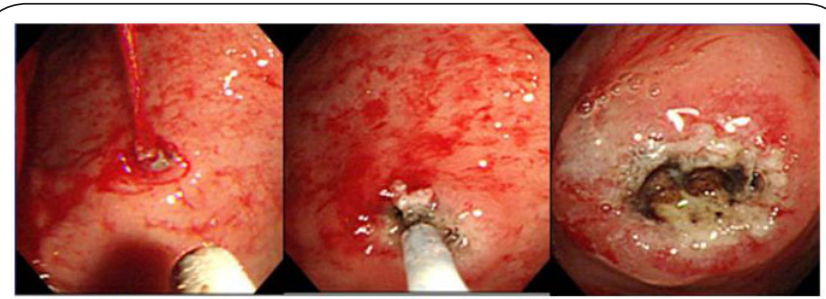

Figure 3. Endoscopic hemostasis with heater probe of case 2. Left: Arterial bleeding of Dieulafoy ulcer in stomach. Middle: Endoscopic treatment with the heater probe. Right: Successful endoscopic hemostasis.

188 patients ( $18.3 \%)$; Ib, 114 patients (11.1\%); Ila, 665 patients (64.8\%); and Illb, 59 patients (5.8\%). Classifications of patients in whom permanent hemostasis was achieved, including patients in whom endoscopic hemostasis was successful without re-bleeding and those who experienced re-bleeding that was eventually controlled by endoscopic hemostasis alone, were as follows: la, 185 patients (98.4\%); lb, 114 patients (100\%); Ila , 665 patients (100\%); and llb, 59 patients (100\%). The total number of patients with endoscopic hemostasis was thus 1,023 (99.7\%) and 3 patients underwent a surgical 
procedure. Re-bleeding was observed in 70 patients (6.8\%). Among these, hemostasis was re-established in 34 patients after only 1 additional endoscopic treatment. Re-establishment of hemostasis required 2 additional endoscopic treatments in 19 patients, one of whom also underwent a surgical procedure because endoscopic hemostasis failed. In 17 patients, hemostasis was re-established after 3 or more additional endoscopic treatments, with 1 patient undergoing surgery after endoscopic hemostasis. In the remaining 1 patient who underwent a surgical procedure, hemostasis could not be achieved with the first endoscopic treatment. Of the patients who underwent a surgical procedure, two were treated in 1988 (hemostasis could not be established endoscopically) and one in 1994 (hemostasis re-established after repeated endoscopic treatment). No patients underwent surgical intervention or IVR after 1994. Of the 19 deaths (1.9\%), nine were due to multi-organ failure and three were due to either infectious or malignant disease. Four deaths were due to bleeding, of which two were due to unrelated conditions (pulmonary hemorrhage, $\mathrm{n}=1$; aortic rupture, $\mathrm{n}=1$ ). As a result, only 2 deaths were recorded as directly associated with ulcer bleeding.

\section{Discussion}

Bleeding gastric ulcer represents the most common form of upper gastrointestinal bleeding. Other similar diseases that occur frequently include esophagogastric varices, duodenal ulcers, and Mallory-Weiss syndrome. The incidence of gastric ulcer varies among health care institutions, but is roughly $25-45 \%$. In our study, a total of 1,152 patients (33.2\%) were diagnosed with gastric ulcer. The male/female ratio is reported as 3:1 to 4:1 [2]. This pathology occurs most commonly in males at 40-70 years old and females at 50-80 years old, with females showing a tendency toward older onset.

Endoscopic treatment of gastrointestinal bleeding, except in the case of varices, includes injection of epinephrine sol-ution in hypertonic saline or pure ethanol [3], thermal coagulation using high-frequency coagulation, microwave electrocoagulation, or a heater probe [4], or mechanical coagulation using hemoclips or snares. At our facility, thermal coagulation with a heater probe is preferred because the technique involved is simple. First, because the tip of the probe merely has to touch the source of bleeding to achieve coagulation, lesions in a tangential direction are easily dealt with. Second, because a spray of water can be supplied directly from the tip of the probe, bleeding blood vessels are easily identified. Third, because both coagulation and the spray are regulated by a foot pedal, the hemostasis procedure can be performed by a single operator. Fourth, because the heat level and amount of water sprayed can be adjusted in steps, all types of bleeding-from arterial to capillary bleeding-can be treated using the same equipment. Performing hemostasis using clips is difficult for lesions that extend in a tangential direction. Clips are also not indicated in cases of capillary bleeding. Localized injection and hemostasis methods using clips require an assistant to deliver the injection or clip, in addition to the endoscopy technician. Endoscopes with a water supply function have recently been developed, but before that, water spraying and treatment could not be achieved simultaneously. Heater probes are free of this disadvantage, they allowing easier hemostasis compared with other treatment methods. One disadvantage of heater probes is that the tip is slippery and movement at the lesion site can make fixation of probe position difficult. However, this problem can be solved with proper manipulation of the probe and endoscope. A growing number of institutions are now using high-frequency hemostatic forceps for soft coagulation of bleeding lesions during endoscopic submucosal dissection (ESD) [5].

Endoscopic examination is recommended to be performed within approximately $24 \mathrm{~h}$ after endoscopic hemostasis therapy for upper gastrointestinal bleeding. This is known as "second-look endoscopy". This procedure can decrease the incidence of re-bleeding by identifying situations where additional treatment may be warranted $[6,7]$, and is also thought to result in an improved hemostasis rate.

Second-look endoscopy is currently recommended for patients with increased risk of bleeding [8], which becomes more likely with the involvement of cost-effectiveness in treatment selection. Gastrointestinal endoscopy and treatment costs in Japan are several times lower in comparison with costs in Europe and the United States, so repeated endoscopy and treatment are more cost-effective in Japan than in those regions. In addition, in order to maintain a high success rate for hemostasis, more patients must undergo second-look endoscopy in an effort to minimize re-bleeding [9].

The reasons why successful hemostasis was achieved using endoscopy as a treatment for bleeding gastric ulcer include the following. First, the physicians who perform endoscopic hemostasis at our facility have many years of experience. There are currently 4 physicians at our facility who perform endoscopic treatment, of whom 1 has 25 years of experience, 2 have $\geq 15$ years of experience, and 1 has $\geq 8$ years of experience. Because these physicians have been performing this type of treatment for many years at the same institution, they are highly proficient, a fact reflected in the treatment outcomes. Second, all hemostasis procedures performed at our facility involve thermal coagulation using a heater probe. Of course, we resort to local injection of pure ethanol or epinephrine in hypertonic saline when necessary, but the basic hemostasis technique we use is application of the heater probe. As mentioned above, heater probe techniques are simple, and because our physicians are highly proficient in this method, we can anticipate improved treatment outcomes. Third, we perform second-look endoscopy for all patients. At our facility, after emergency treatment of ulcers, including varicosities and Mallory-Weiss syndrome, we always perform second-look endoscopy (except in cases of imminent death), with additional 
Inoue et al. Gastroenterological and Intestinal Systems 2014,

treatment as necessary. This approach not only reveals cases of re-bleeding, but also improves treatment outcomes.

\section{Conclusions}

Here we reviewed patients with bleeding gastric ulcer treated at our institution between 1987 and 2011. We treated at least 30 patients a year during the study period, approximately $90 \%$ of whom underwent endoscopic treatment, with a success rate of $99.7 \%$. Prior to 1995 , endoscopic treatment failed in some patients, but no failures were reported after 1995. We therefore believe that endoscopic hemostasis offers sufficient therapeutic value.

\section{Competing interests}

The authors declare that they have no competing interests.

\section{Authors' contributions}

\begin{tabular}{|l|c|c|c|c|c|c|c|c|c|c|}
\hline Authors' contributions & YI & YF & MO & SK & MS & HS & HN & MK & YS & SE \\
\hline $\begin{array}{l}\text { Research concept and } \\
\text { design }\end{array}$ & $\checkmark$ & -- & -- & -- & -- & -- & -- & -- & -- & -- \\
\hline $\begin{array}{l}\text { Collection and/or } \\
\text { assembly of data }\end{array}$ & $\checkmark$ & $\checkmark$ & $\checkmark$ & $\checkmark$ & $\checkmark$ & $\checkmark$ & $\checkmark$ & $\checkmark$ & -- & -- \\
\hline $\begin{array}{l}\text { Data analysis and } \\
\text { interpretation }\end{array}$ & $\checkmark$ & -- & -- & -- & -- & -- & -- & -- & -- & -- \\
\hline Writing the article & $\checkmark$ & -- & -- & -- & -- & -- & -- & -- & -- & -- \\
\hline $\begin{array}{l}\text { Critical revision of the } \\
\text { article }\end{array}$ & $\checkmark$ & -- & -- & -- & -- & -- & -- & -- & -- & -- \\
\hline Final approval of article & $\checkmark$ & -- & -- & -- & -- & -- & -- & -- & -- & -- \\
\hline Statistical analysis & $\checkmark$ & $\checkmark$ & -- & -- & -- & -- & -- & -- & $\checkmark$ & $\checkmark$ \\
\hline
\end{tabular}

Publication history

Editor: Rakesh Kumar Tandon, Pushpawati Singhania Research Institute, India.

EIC: Walter Fries, University of Messina, Italy.

Received: 14-Sep-2014 Final Revised: 20-Nov-2014

Accepted: 29-Nov-2014 Published: 06-Dec-2014

\section{References}

1. Forrest JA, Finlayson ND and Shearman DJ. Endoscopy in gastrointestinal bleeding. Lancet. 1974; 2:394-7. | Article | PubMed

2. Sakaguchi $M$, Takao $M$ and Hashimoto $T$. The clinical study of endoscopic hemostasis for upper gastrointestinal bleeding over A 10-year period. Gastroenterol. Endosc. 2010; 52:2678-2686.

3. Asaki S. Tissue solidification in coping with digestive tract bleeding: hemostatic effect of local injection of $\mathbf{9 9 . 5 \%}$ ethanol. Tohoku J Exp Med. 1981; 134:223-7. I Article I PubMed

4. Protell RL, Rubin CE, Auth DC, Silverstein FE, Terou F, Dennis M and Piercey JR. The heater probe: a new endoscopic method for stopping massive gastrointestinal bleeding. Gastroenterology. 1978; 74:257-62. | PubMed

5. Sugiyama T, Dozaiku $T$ and Toyonaga $T$ et al. The usefulness of $4+1$ contact method using soft coagulation for bleeding gastric ulcers. Gastroenterol. Endosc. 2006; 48:204-211.

6. Chiu PW, Lam CY, Lee SW, Kwong KH, Lam SH, Lee DT and Kwok SP. Effect of scheduled second therapeutic endoscopy on peptic ulcer rebleeding: a prospective randomised trial. Gut. 2003; 52:1403-7. | Article | PubMed Abstract | PubMed Full Text

7. Marmo R, Rotondano G, Bianco MA, Piscopo R, Prisco A and Cipolletta L.
Outcome of endoscopic treatment for peptic ulcer bleeding: Is a second look necessary? A meta-analysis. Gastrointest Endosc. 2003; 57:62-7. | Article I PubMed Abstract I PubMed Full Text

8. Barkun AN, Bardou M, Kuipers EJ, Sung J, Hunt RH, Martel M and Sinclair $P$. International consensus recommendations on the management of patients with nonvariceal upper gastrointestinal bleeding. Ann Intern Med. 2010; 152:101-13. I Article I PubMed

9. Inoue $\mathrm{Y}$, Fujino $\mathrm{Y}$ and Onodera $\mathrm{M}$ et al. Endoscopic hemostasis of nonvariceal gastrointestinal bleeding. Intern. J Clin. Med. 2014; 5:11471154.

\section{Citation:}

Inoue Y, Fujino Y, Onodera M, Kikuchi S, Sato M, Sato H, Noda H, Kojika M, Suzuki Y and Endo S. Clinical outcome of endoscopic hemostasis with heater probe coagulation for bleeding gastric ulcer. Gasteroentrol Intest Syst. 2014; 2:1.

http://dx.doi.org/10.7243/2054-4154-2-1 